\title{
Mapeamento social participativo e cidadania: planejamento e gestão socioambiental de território indígena
}

\author{
Participative social mapping and citizenship: socio-environmental planning and \\ management of indigenous territory
}

Jacqueline Cunha de Vasconcelos Martins $^{1}$
Edson Vicente da Silva ${ }^{2}$
Paulo Cesar Moura da Silva ${ }^{3}$

\begin{abstract}
1 Mestre e Docente da Universidade Federal Rural do Semi-Árido. E-mail: jacquelinevasconcelos@ufersa.edu.br
2 Doutor e Docente de Geografia da Universidade Federal do Ceará. E-mail: cacauceara@gmail.com

3 Doutor e Docente da Universidade Federal Rural do Semi-Árido. E-mail: paulo.moura@ufersa.edu.br

4 Doutor e Docente de Geografia da Universidade Federal do Ceará. E-mail: jeovahmeireles@gmail.com
\end{abstract}

RESUMO: Os povos autóctones brasileiros, historicamente perderam numerosa população, diversidade cultural e extensos territórios e continuam oprimidos em seus direitos. No Estado do Rio Grande do Norte, indígenas remanescentes têm reivindicado seus direitos em várias instâncias governamentais. Neste artigo são apresentadas temáticas teórico-metodológicas que envolvem pesquisa sobre cartografia socioambiental em comunidade indígena e objetiva subsidiar a sustentabilidade territorial e socioeconômica. A abordagem interdisciplinar via etnomapeamento participativo visa contribuir para o empoderamento, visibilidade e valorização sociocultural local, na perspectiva do planejamento e gestão territorial que devem fortalecer a luta pela demarcação territorial; além de contribuir para o conhecimento nas ciências ambientais.

Palavras-chave: Autodeterminação indígena. Etnoecologia Cartografia social. Sustentabilidade.

ABSTRACT: Brazilian indigenous peoples have historically lost large populations, cultural diversity and extensive territories and remain oppressed in their rights. In the State of Rio Grande do Norte, indigenous remnants have claimed their rights in various governmental instances. This article presents theoretical-methodological topics that involve research on social-environmental cartography in indigenous communities and aims to support territorial and socioeconomic sustainability. The interdisciplinary approach through participatory ethnomapulation aims to contribute to the empowerment, visibility and local socio-cultural valuation, from the perspective of territorial planning and management that should strengthen the struggle for territorial demarcation; besides contributing to the knowledge in the environmental sciences. Keywords: Indigenous self-determination. Ethnoecology. Social cartography. Sustainability.

Sumário: Introdução - 1 Autodeterminação Indígena - 2 Etnoecologia, Empoderamento e Sustentabilidade 3 Cartografia Social e Cidadania: Ferramenta de Planejamento e Gestão Socioambiental - 4 Aspectos Metodológicos - 5 Contextualização e Resultados Preliminares - Considerações Finais - Referências

\section{INTRODUÇÃO}

Historicamente, em consequência do sistema colonialista, os povos autóctones ao território brasileiro perderam numerosa população, grande parte da diversidade cultural e extensos territórios. Os atuais 
remanescentes, por sua vez, continuam a ser oprimidos em seus direitos políticos, sociais e culturais e, ainda permanecem condicionados às políticas indigenistas (GOMES, 2010), afetando o exercício pleno da cidadania desses povos.

Nessa perspectiva, em abordagem sobre a possibilidade de uma cultura emancipatória, Santos (2001) destaca aspectos sobre a territorialização e a consequente exclusão social de grupos oprimidos, considerados cidadãos apenas formalmente. Afirma que o processo de globalização neoliberal, dentre outras consequências, tem promovido a desterritorialização desses grupos e destaca como exemplo de grande manifestação da territorialização o movimento indígena iniciado nas décadas de 1980 e 1990. "O movimento indígena é uma grande afirmação de que há relações sociais que são escritas em territórios e que só fazem sentido enquanto parte deles" (SANTOS, 2001, p.3). O autor destaca a estreita identidades desses povos com seus territórios.

Na realidade do Rio Grande do Norte $(\mathrm{RN})$, comunidades indígenas têm reivindicado seus direitos em várias instâncias governamentais. O marco da mobilização é o ano 2005 onde, em audiência pública na Assembleia Legislativa do Estado, três comunidades se apresentaram como remanescentes indígenas: Mendonça do Amarelão, Caboclos do Assu e Eleotérios do Catu (VIEIRA e KÓS, 2017), além de outras que posteriormente fizeram o autor reconhecimento (GUERRA, 2017).

Mesmo ainda não constando nos mapas oficiais, o Conselho Indigenista Missionário (CIMI, 2011) enfatiza que a demarcação de Terras Indígenas (TI) no RN é reivindicada desde 2005 e a Associação Nacional dos Povos Indigenistas (ANAÍ, 2016), que faz o acompanhamento da situação fundiária, igualmente destaca a existência destes povos em terras potiguares ${ }^{1}$. Além disso, pesquisas têm sido desenvolvidas nos programas de pós-graduação de universidades públicas regionais sobre indígenas no estado e região, a exemplo dos estudos sobre: Potiguara (VIEIRA, 2012 e PEREIRA, 2015); Mendonça do Amarelão (GUERRA, 2007 e CAMPOS, 2014); Eleotérios do Catu (SILVA, 2007); Caboclos do Assu (OLIVEIRA, 2014) e, sobre o processo de invisibilidade e reconhecimento dos indígenas potiguares (VIEIRA, KÓS, 2017).

Assim, esta pesquisa tem por objetivo apresentar temáticas e metodologias que norteiam a pesquisa sobre cartografia socioambiental em comunidade indígena do RN, visto que o etnomapeamento participativo contribui para o empoderamento, visibilidade e valorização sociocultural; bem como subsidia o planejamento, a gestão territorial e políticas públicas socioambientais na perspectiva da sustentabilidade local e fortalecimento da luta por seus territórios.

\section{AUTODETERMINAÇÃO INDÍGENA}

A historiografia clássica aponta para o "desaparecimento” de indígenas nos Estados do RN e Piauí (MACEDO, 2011). Conforme dados de 1844 havia 6.795 indígenas no RN, mas no levantamento de 1872 já “não constavam mais" (MONTEIRO, 2015). Inicia-se então o processo histórico de "invisibilidade" e, mesmo na atualidade, essas comunidades nem mesmo constam nos mapas oficiais da Fundação Nacional do Índio (FUNAI, 2017).

Todavia, nova realidade tem se configurado. Povos indígenas vêm ocupando espaços em organismos internacionais como a Organização das Nações Unidas (ONU) e têm buscado o resgate da sua identidade

\footnotetext{
${ }^{1}$ Os nascidos no RN são chamados de potiguares ou norte-rio-grandenses. Potiguar é de origem tupi e significa "comedor de camarão" e designava os potiguaras - povos indígenas originários que habitavam a região (MONTEIRO, 2015).
} 
etnocultural. No Brasil, um reflexo positivo é o último Censo do Instituto Brasileiro de Geografia e Estatística (IBGE), em 2010.

O censo possibilitou a autoidentificação, onde considera indígena: "pessoa, residente ou não em terras indígenas, que se declarou indígena na investigação sobre cor ou raça"; ou a pessoa que se considera indígena, “[...] de acordo com suas tradições, costumes, cultura, antepassados etc.” Todavia, o órgão destaca que é complexo obter informações sobre indígenas por vários fatores como "receio de manifestar sua identidade por preconceito e discriminação, ou [...] devido às experiências vividas anteriormente” (IBGE, 2010 p.41; 52).

A Declaração sobre os Direitos dos Povos Indígenas (ONU, 2007) destaca no Art. 3 que estes têm direito à livre determinação e a Convenção 169 da Organização Internacional do Trabalho (OIT, 2011) estabelece a autoidentidade indígena como instrumento fundamental, ao enfatizar que nenhum Estado ou grupo social tem o direito de negar a identidade a um povo indígena que se reconheça. O referido documento é considerado um instrumento para a inclusão social de milhões de pessoas.

No mesmo entendimento, os princípios estabelecidos no Plano Setorial para as Culturas Indígenas (BRASIL, 2012) ressaltam entre outras coisas: autodeterminação e autonomia dos povos indígenas; etnodesenvolvimento; e protagonismo indígena e prevê ainda mapeamento, registro e difusão das culturas indígenas.

Ainda há uma visão equivocada predominante no senso comum dos brasileiros sobre as culturas nativas, que "para serem respeitadas" devem permanecer semelhantes ao período das colonizações. Isso vale especialmente em relação aos indígenas que habitam próximo à costa brasileira, em que os impactos socioculturais da colonização europeia são mais evidentes. Considerando que as culturas são dinâmicas e influenciam-se mutuamente, não significa perda de identidade.

Nesse contexto, a autodeterminação é fundamental, pois visa afirmar os grupos indígenas enquanto sujeitos capazes de traçarem estratégias de defesa dos seus direitos, negociando a melhor forma para viverem de acordo com suas pautas culturais Enquadram-se na categoria indígena diferentes grupos étnicos tanto entre si como das sociedades nacionais, os quais reivindicam direitos baseados no princípio dos Direitos Originários (CALEFFI, 2015).

Em 2015, atendendo à recomendação do Ministério Público Federal, a FUNAI instituiu um Grupo Técnico para identificar e delimitar as terras de uma das comunidades indígenas do RN (VIEIRA e KÓS, 2017). Embora tenha sido contemplada somente uma comunidade, já é um começo na possibilidade de oficializar o reconhecimento.

Nesse contexto, o desafio do Estado para apoiar as políticas indigenistas não assimilacionistas de comunidades não isoladas é bem significativo, de modo que essa valorização se sobreponha às relações de dominação ou de dependência dos costumes e valores não indígenas (ANAÍ, 2016).

\section{ETNOECOLOGIA, EMPODERAMENTO E SUSTENTABILIDADE}

A etnoecologia é a interseção entre as ciências naturais e humanas, ao compreender como indissociáveis as relações planta-animal-humano e considerar os conhecimentos e experiências dos povos tradicionais na interpretação dos fenômenos naturais (POSEY et al., 1984). A pesquisa etnoecológica se ocupa principalmente das condições nas quais os processos de aquisição e de transformação do conhecimento estão inseridos (PRADO e MURRIETA, 2015).

De modo que a etnoecologia contribui para a elaboração de instrumentos de gestão da biodiversida- 
de, a exemplo do etnomapeamento desenvolvido por meio de processos participativos de diagnóstico e planejamento para uso sustentável do território e da biodiversidade (SOUZA, BASSI e KUBO, 2011).

Portanto, o etnomapeamento que é parte do diagnóstico etnoambiental, é realizado por um conjunto de técnicas e ferramentas que possibilitam a reflexão da comunidade sobre seu contexto e a expressão desta por meio da cartografia (CARDOSO e GUIMARÃES, 2012).

Nesta perspectiva, é fundamental destacar a importância do empoderamento dos conhecimentos tradicionais pelas comunidades, que em sua essência se traduz em democracia, fortalecimento e autonomia. Por isso, este conceito tem ocupado relevante espaço nas ciências sociais (ALMEIDA, 2015).

A seguir são apresentados dois interessantes exemplos de empoderamento com base em conhecimentos etnoecológicos. A descoberta do guaraná pelos Sateré-Mawé da Amazônia brasileira, primeiro povo indígena a utilizar e comercializar o guaraná como produto próprio, ocupando ainda papel de destaque em movimentos colaborativos nacionais e internacionais e importante referência de sustentabilidade (FIGUEROA, 2016). O outro caso é referente à comunidade indígena Boruca, na Costa Rica, em que as máscaras coloridas de festas tradicionais, símbolo da luta contra os colonizadores espanhóis, passaram a ser utilizadas pelas mulheres como uma fonte de renda (STALLAERT, 2016).

O paradigma colonial e epistemológico imposto globalmente, empobrece a grande diversidade de culturas e epistemologias não adequadas aos objetivos da dominação colonial e capitalista, para isso é necessário lembrar e reinventar o que significa defender que há um ocidente não-ocidentalista que a partir dele é possível pensar um tipo novo de relações interculturais e inter-epistemológicas (SANTOS, 2010). Uma vez que as relações sociais são sempre culturais e políticas, todo conhecimento considerado válido é sempre contextual, ou seja, as experiências sociais resultam de vários conhecimentos com diferentes critérios de validade (SANTOS, 2010).

Por isso, é necessário dar preferência aos conhecimentos que garantam maior envolvimento dos grupos sociais e reavaliar as intervenções tanto da ciência como de outros saberes nas relações entre sociedade e natureza, desde a concepção, execução e controle, ou seja, é necessária uma ecologia de saberes. Além disso, reconhecer a pluralidade epistemológica interna e externa à ciência, com diferenciados critérios de validade, possibilita alternativas nessa diversidade enriquecedora das experiências sociais (SANTOS, 2010). Assim, as dinâmicas interconectadas de empoderamento, etnodesenvolvimento e etnorresistência constituem metodologias anticoloniais (STALLAERT, 2016).

Considerando ainda que o caminho da sustentabilidade deve partir do local, respeitando os ecossistemas com suas diversas formas de vida, viabilizando o desenvolvimento e priorizando o ser humano em detrimento do capital (BOFF, 2012), é necessário planejamento em uma abordagem sistêmica,C visando passar de um modelo econômico predatório de crescimento para um estado de economia constante (SACHS, 2012).

As populações tradicionais têm categorias próprias de nomear e classificar o ambiente. Por conviverem com a biodiversidade não enxergam como um recurso natural, mas como seres vivos que têm também valor simbólico e não apenas de uso (SILVA et al, 2016). Assim, a etnoecologia é fundamental para a sustentabilidade, uma vez que contempla vários aspectos, como o social, o ambiental e o econômico, valorizando o empoderamento dos conhecimentos tradicionais de comunidades indígenas.

3 CARTOGRAFIA SOCIAL E CIDADANIA: FERRAMENTA DE PLANEJAMENTO E GESTÃO SOCIOAMBIENTAL 
A cartografia social é uma técnica presente na ciência cartográfica, que enfatiza o conhecimento popular, simbólico e cultural, como meio de produzir o mapeamento de territórios tradicionais e, assim, buscar entre outras coisas a conservação e o reconhecimento de suas culturas de forma sustentável (GORAYEB, MEIRELES e SILVA, 2015), essencial para o planejamento participativo de gerenciamento de paisagens, compreender como as comunidades locais percebem seus ambientes.

Neste sentido, a cartografia social tem se configurado importante instrumento de controle e empoderamento, pois os mapas sociais são representações vivas de territórios comunitários e possibilitam a troca de experiências entre os saberes tradicionais e a inserção de novas tecnologias da geoinformação (GORAYEB, MEIRELES e SILVA, 2015).

Para esses autores seu aspecto interdisciplinar, a cartografia social utiliza fundamentos de diversas ciências, tornando este viés fundamental na produção do conhecimento devido ao caráter dialético da realidade social (FRIGOTTO, 2008). Além disso, dadas as implicações políticas inerentes aos mapas, uma vez que são eles próprios objetos de ação política (ACSELRAD, 2008), na realidade indígena potiguar, a cartografia social é imprescindível por possibilitar a construção dos mapas sociais com a participação ativa das comunidades, que definem os elementos considerados identitários.

Desse modo, o planejamento das paisagens por meio da cartografia social, de base histórico-territorial, cultural e com vistas à gestão ambiental, é uma forma eficaz de atender às exigências científicas e técnicas e, ao mesmo tempo, ser coletivamente construído (RODRIGUEZ e SILVA, 2016). Ainda, o planejamento das unidades de paisagem em Terras Indígenas (TI) é importante para orientar adequadamente as formas de uso e ocupação de solo, além de ajudar na preservação cultural (MEIRELES, 2011).

\section{ASPECTOS METODOLÓGICOS}

A pesquisa em curso, com enfoque qualitativo (RICHARDSON, 2014), consta de quatro estágios de investigação, realizados por meio de oficinas, conforme roteiro de planejamento das paisagens adaptado de Rodriguez e Silva (2016). O primeiro estágio de organização e inventário, identifica, caracteriza e cartografa as unidades espaciais, faz o inventário das condições naturais e socioeconômicas e o mapeamento das unidades socioambientais. No segundo estágio é feita a análise das propriedades do espaço natural, das unidades espaciais e das paisagens culturais.

O terceiro estágio de diagnóstico, tem por objetivo esclarecer a situação dos sistemas ambientais em decorrência da utilização e exploração, para avaliar o potencial dos recursos e serviços ambientais e identificar problemas de degradação ambiental e vulnerabilidades socioambientais e culturais. No quarto estágio é feita a projeção de cenários, onde são elaboradas propostas de usos dos sistemas ambientais numa perspectiva espacial holística, considerando as várias dimensões que compõem as comunidades naturais, sociais e culturais.

A operacionalização se dá por meio de oficinas participativas de cartografia social, caminhadas guiadas, diálogos, observação participante e registro fotográfico (CARDOSO e GUIMARÃES, 2012), além da utilização de geotecnologias como fotografias aéreas, imagens de satélite e Sistema de Posicionamento Global (GPS), conforme explicado por Gorayeb, Meireles e Silva (2015). Para a confecção dos mapas são utilizadas essas e outras ferramentas tecnológicas de geoprocessamento como o software de acesso livre Quantum Geographic Information System (QGIS), versão 2.14 (QGIS, 2017), que é um Sistema de Informação Geográfica (SIG), com acesso a bases de dados públicos como o Instituto Nacional de Pesquisas Espaciais (INPE). 


\section{CONTEXTUALIZAÇÃO E RESULTADOS PRELIMINARES}

O município de João Câmara-RN (figura 1) está localizado a $80 \mathrm{~km}$ de Natal, capital do Estado, com população estimada em 35.087 pessoas, onde 30\% vive no ambiente rural. No aspecto econômico, o Produto Interno Bruto (PIB) per capita de R \$22.230,29 em 2015, sendo o décimo maior do Estado, de um total de 167 municípios. O Índice de Desenvolvimento Humano Municipal (IDHM), com variação de 0 a 1 que engloba dados quantitativos relacionados à educação, esperança de vida ao nascer e PIB, em 2010 foi de 0,595, abaixo da média nacional que no mesmo ano foi de 0,699 (IBGE, 2017).

Figura 1 - Localização do município de João Câmara-RN

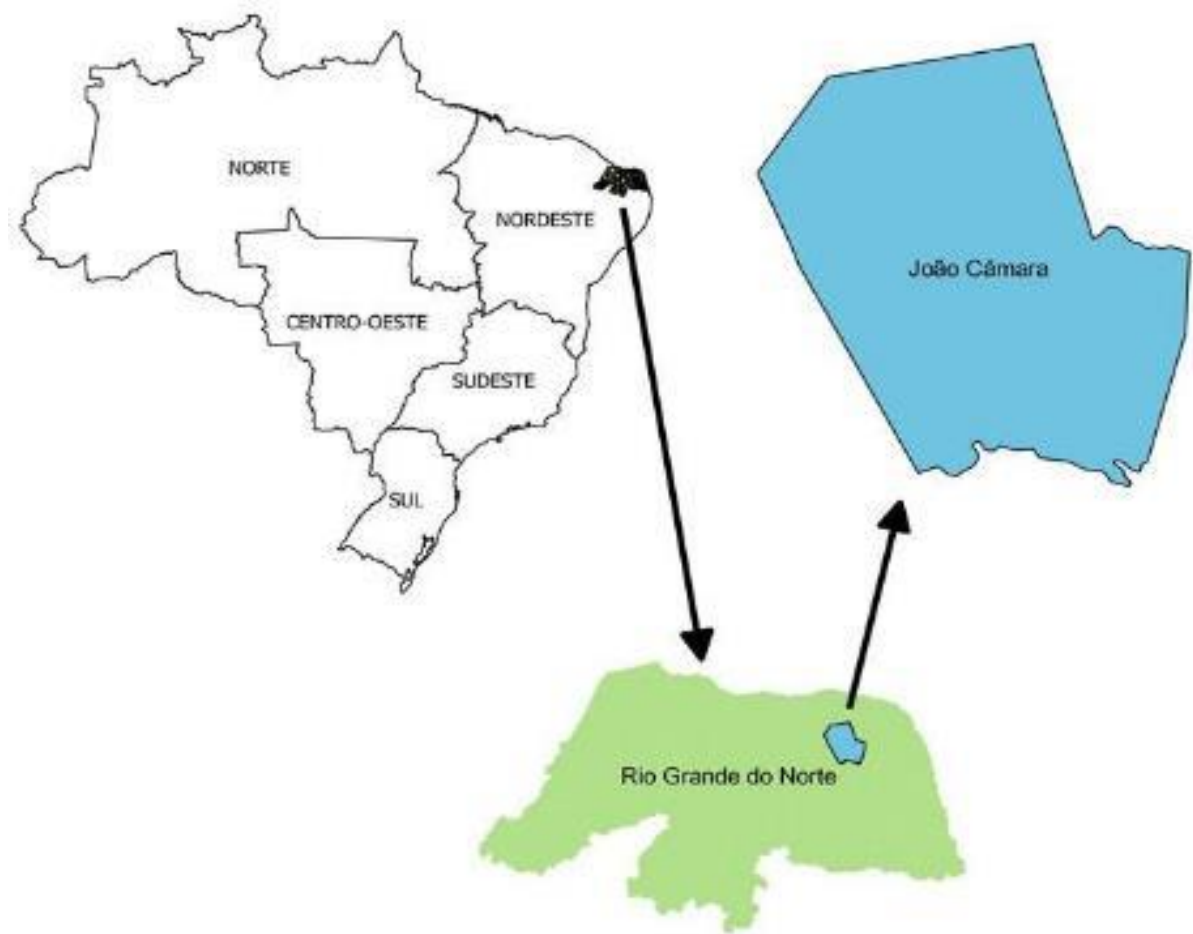

Fonte: Autores (2018).

A Aldeia Amarelão² localizada na região do Mato Grande, na zona rural de João Câmara-RN, fica a $14 \mathrm{~km}$ da sede, sendo $10 \mathrm{~km}$ na BR 406 e $4 \mathrm{~km}$ de estrada de terra. Com população estimada em 1.100 pessoas distribuídas em cerca de 300 famílias (SILVA, 2017). A localidade tem os seguintes limites geográficos: BR 406, norte; Assentamento Santa Teresinha, sul; Morada Nova, leste; e Serrote de São Bento, oeste (GUERRA, 2017).

A vegetação predominante é de caatinga, jurema (Mimosa tenuiflora), marmeleiro (Cydonia oblonga), cactos (Cactaceae) e bromélias (Bromeliaceae) entre outras. E os animais mais presentes são camaleões (Chamaeleonidae), tatu peba (Euphractus sexcinctus), preá (Cavia aperea), raposa (Vulpes vulpes), veado (Artiodactyla), além de vários tipos de aves (SILVA, 2017).

De etnia potiguara e origem ligada aos índios Tapuia falantes do Tupi, os Mendonça do Amarelão

\footnotetext{
20 critério de definição da área da pesquisa tem por base a Qualificação da Reivindicação de Terras, correspondente à primeira etapa do processo de regularização de TI (CAMPOS, 2014); além do atual grau de organização sóciopolítico e envolvimento de lideranças da comunidade no movimento indígena (GUERRA, 2017).
} 
recebem essa denominação devido ao ritual de culto ao sol, celebrado por seus antepassados (SILVA, 2017). As migrações forçadas da família extensa Mendonça, proveniente do Estado da Paraíba, ocorreram na primeira metade do século XIX e se estenderam até o século XX, motivadas por diferentes adversidades como conflitos por terras, epidemias e condições climáticas.

Nos anos 1930 e 1940, à medida que perderam seus territórios que foram sendo ocupados pelo político e empreendedor João Câmara para plantação de algodão, cana de açúcar e agave, foram inseridos na mão de obra. Entre os anos 1930 e 1950 houve muitos tremores de terra na região e algumas famílias se deslocaram para a zona norte de Natal, o Amarelão Novo. Em Serrote de São Bento, também, se encontra população da família extensa Mendonça (GUERRA, 2017).

Em meados da década de 1980, os Mendonça passaram a ter autossustentação com o beneficiamento da castanha de caju. Nos anos 1990, na busca para recuperar seus territórios dos latifundiários, na luta conjunta com o Movimento dos Trabalhadores Sem Terra (MST) conquistaram junto ao Instituto Nacional de Colonização e Reforma Agrária (INCRA) o Assentamento Santa Teresinha, um dos primeiros do RN.

O nome é uma homenagem a Irmã Teresinha de Galles, da congregação do Imaculado Coração de Maria, apoiadora fundamental nas lutas dos Mendonça. A infraestrutura local da Aldeia Amarelão é composta por uma escola municipal de ensino fundamental; uma associação; um precário posto de atendimento médico; uma quadra de futebol e duas igrejas, uma católica e outra evangélica (GUERRA, 2017). Atualmente, a principal fonte de renda da Aldeia Amarelão é o beneficiamento da castanha de caju, comercializada em João Câmara, Natal, região, além de outros estados.

É a maior beneficiadora de castanha do RN. Também desenvolvem outros produtos derivados da castanha como bolos, cocadas e farinha de castanha na cozinha comunitária da Associação Comunitária do Amarelão (ACA), além do Artesanato. A comercialização é feita na própria associação e em João Câmara. Outras iniciativas alternativas de geração de renda são desenvolvidas como criação de animais de pequeno porte e, bovinos por algumas pessoas para produzir leite e esterco destinados à comercialização (SILVA, 2017).

Merecem destaque algumas unidades de paisagem da aldeia ou pontos de memória com aspectos naturais e culturais preservados. A gameleira, uma árvore com mais de dois séculos, onde realizavam a feira para troca e compra de produtos da pesca, caça e agricultura. A pedra das letras, com registro de escritas rupestres dos primeiros povos que habitaram a região. Os tanques de pedra, um lajedo com fendas formadas naturalmente, onde em seu entorno corre um riacho no período das chuvas.

A pedra do sino, que ao bater na mesma com uma pedra ecoa um som semelhante ao de sino e a Lagoa da Cobra. Dentre os locais antigos têm destaque: a casa de taipa, construída há mais de 70 anos e ainda habitada, a cacimba salgada, local que marca a divisão social de territórios nas comunidades e onde as mulheres da comunidade lavavam roupas, a linha férrea, que também marca a divisão dos territórios dos Mendonça, sendo o primeiro empreendimento de grande porte, onde os Mendonça foram usados na mão de obra e delimita a área do Amarelão entre o Assentamento Santa Terezinha, o umbuzeiro, que representa área de retomada, usado como ponto de apoio para visualização (SILVA, 2017).

$\mathrm{Na}$ escola da aldeia são ensinados o Toré, dança tradicional indígena e a língua Tupi, com o objetivo de preservar a cultura dos antepassados. Uma liderança da comunidade afirma que as crianças já cantam os cantos do Toré em tupi (SILVA, 2017). Em comunidades indígenas, sobretudo, as prioridades precisam ser evidenciadas pelos atores sociais locais.

Um bom exemplo é o Projeto Nova Cartografia Social da Amazônia (PNCSA, 2014), um caso 
concreto em que a cartografia resultou em conquistas significativas para as comunidades, pois possibilitou a criação de políticas sociais e ambientais direcionadas às comunidades tradicionais. Por meio da autocartografia, o referido projeto promove conhecimento dos processos de ocupação da região e tem sido um instrumento para o fortalecimento local e das lutas em prol da gestão territorial contra a devastação da floresta e extermínio das culturas tradicionais.

Outro caso interessante é o da etnia Tsimane, um grupo de caçadores-horticultores da Amazônia boliviana, em que as prioridades locais na gestão da paisagem possibilitaram determinar as áreas destinadas ao uso da comunidade, diferenciando as que são utilizadas para atividades econômicas de forma sustentável e as que são exclusivas para conservação (RIU-BOSOMS et al., 2015).

O movimento indígena crescente no RN desde 2005 e tem fortalecido a afirmação étnica dos Mendonça do Amarelão. São significativos os avanços no campo político, por meio de articulações com parceiros e colaboradores de instituições, apesar das adversidades de medidas governamentais. Algumas das principais temáticas de discussão são: respeito à diferenciação étnica e direito à educação e saúde diferenciadas, territorialidade e sustentabilidade (GUERRA, 2017). Todavia, dentre os principais problemas vivenciados atualmente pelas comunidades indígenas no $\mathrm{RN}$, destacam-se os conflitos fundiários com empresários do ramo imobiliário e a indústria sucroalcooleira com extensas áreas de plantios de cana de açúcar (VIEIRA e KÓS, 2017).

Vale reforçar que com base no planejamento das paisagens proposto por Rodriguez e Silva (2016), o objetivo da pesquisa com a referida comunidade indígena é fazer inventário e diagnosticar as vulnerabilidades e potencialidades socioambientais e culturais, bem como elaborar propostas coletivas de uso sustentável do território e da biodiversidade numa perspectiva holística, além de conhecer a atual configuração sociocultural e o contexto histórico de invisibilidade e resistência.

Assim, resultará na elaboração de mapas temáticos com potencialidades e fragilidades socioambientais e culturais para o planejamento e gestão sustentável dos seus territórios, possibilitando mais autonomia, maior empoderamento dos conhecimentos tradicionais e visibilidade para o enfrentamento na legitimação dos territórios, mensurado por meio da tecnologia do etnomapeamento.

O caminho da sustentabilidade deve partir do local, respeitando os ecossistemas com suas diversas formas de vida, viabilizando o desenvolvimento e priorizando o ser humano em detrimento do capital (BOFF, 2012). Para tanto, é necessário planejamento em uma abordagem sistêmica como defendido por SACHS (2012) e CAPRA (2001).

\section{CONSIDERAÇÕES FINAIS}

De acordo com a alternativa de um diálogo horizontal entre os diferentes conhecimentos ou uma ecologia de saberes, o reconhecimento de estudos etnológicos, é fundamental para embasar o desenvolvimento de métodos científicos. Desse modo, a etnoecologia é fundamental para a sustentabilidade, uma vez que valoriza o empoderamento dos conhecimentos tradicionais e contempla vários aspectos como o social, o ambiental e o econômico (SANTOS, 2010).

No processo de emergência étnica vivenciado por comunidades indígenas do RN, o mapeamento social participativo que tem as comunidades como protagonistas do processo, serve para provar que precisam de seu território, pois é onde se desenvolvem e preservam suas práticas tradicionais, contribuindo assim para a autonomia e o etnodesenvolvimento local. 
É importante salientar que o aspecto que diferencia a cartografia social da construção convencional de mapas é por ser baseada nas percepções ambientais dos atores sociais sobre os aspectos ecológicos, sociais e simbólicos locais, ou seja, pelas pessoas que vivem na comunidade e conhecem a realidade local. Além disso, é uma tecnologia social com possibilidade de atualização constante e que tem caráter interdisciplinar, ao utilizar os fundamentos de várias áreas do conhecimento científico como humanas e sociais, naturais e ambientais.

Assim, dada a complexidade das questões socioambientais e etnoculturais, a realização do mapeamento social participativo na comunidade indígena Mendonça do Amarelão, possibilita a valorização dos etnoconhecimentos e a construção da cartografia social como ferramenta para subsidiar o planejamento e a gestão socioambiental na perspectiva do desenvolvimento sustentável. Tais conhecimentos contribuem para o empoderamento e maior visibilidade e podem ser uma importante ferramenta para fortalecer a luta pela legitimação e tardia demarcação dos seus territórios.

\section{REFERÊNCIAS}

ACSELRAD, H. (organizador) Cartografias sociais e territórios. Rio de Janeiro: Universidade Federal do Rio de Janeiro, Instituto de Pesquisa e Planejamento Urbano e Regional, 2008. (Coleção Território, ambiente e conflitos sociais; n.1. Disponível: <http://www.ettern.ippur.ufrj.br/central_download.php?hash=467ab838abf48499b7dbb9f41 fa3268c\&id=8> Acesso: 23.06.2017.

ALMEIDA, A.C. 0 empoderamento de lideranças indígenas Kaingang no sul do Brasil. Interações (Campo Grande) [online]. 2015, vol.16, n.2, p.407-419. Disponível: <http://www.scielo.br/scielo.php?script=sci_arttext\&pid=S1518-70122015000200407\&lng= pt\&nrm=iso $>$ Acesso 05.08.2017.

ANAÍ - ASSOCIAÇÃO NACIONAL DE AÇÃO INDIGENISTA. Acompanhamento da situação fundiária das terras indígenas do Rio Grande do Norte. Disponível: <http://www.anai.org.br/povos_rn.asp>. Acesso: 17.11.2016.

BOFF. L. Sustentabilidade: o que é, o que não é. Petrópolis/RJ: Vozes, 2012.

BRASIL. Ministério da Cultura. Secretaria da Identidade e da Diversidade. Plano Setorial para as Culturas Indígenas. 2012. Disponível: <http://www.cultura.gov.br/documents /10901/1131439/1398784157745plano_setorial_culturas_indigenas1.pdf/fd61f6a9-46ac4378-8e9f-9b3e8321e2d2> Acesso: 17.06.2017.

CALEFFI, P. “O que é ser índio hoje?” A questão indígena na América Latina/Brasil no início do século XXI. Red de Revistas Científicas de América Latina y el Caribe, España y Portugal, 2015. Disponível: <http://www.redalyc.org/html/162/16200702/>. Acesso: 15.07.2017.

CAMPOS T. M. Entrevista concedida a SANTOS, R.S. Os índios no tempo presente. Revista de Humanidades: dossiê histórias indígenas. v.15, n.35, p.166-190, 2014. Disponível: < https://periodicos.ufrn.br/ mneme/article/view/8088> Acesso: 16.10.2016.

CAPRA, F. O ponto de mutação. São Paulo: Cultrix, 2001.

CARDOSO, T.M.; GUIMARÃES, G.C. (Orgs.). Etnomapeamento dos Potiguara da Paraíba. Brasília: FUNAI/CGMT/CGETNO/CGGAM, 2012. (Série Experiências Indígenas. Disponível em <http://www.funai.gov.br/arquivos/conteudo/cogedi/pdf/Series/Etnomapea mento_Potiguara/LivroPotiguara-baixa.pdf> Acesso: 07.08.2017. 
CONSELHO INDIGENISTA MISSIONÁRIO - CIMI. Reivindicada desde 2005, Funai começa trabalho de demarcação no RN. 2011. Disponivel <http://www.cimi.org.br/ site/pt-br/index.php?system=news\&action=read\&id=5662> Acesso: 15.11.2016.

FIGUEROA, A.L.G. Guaraná, a máquina do tempo dos Sateré-Mawé. Ciências Humanas. [online]. 2016, vol.11, n.1 p.55-85. Disponível: <http://www.scielo.br/scielo.php ?script=sci_arttext\&pid=S1981-81222016000100055\&lng=pt\&nrm=iso>. Acesso: 06.08.2017.

FRIGOTTO, G., A interdisciplinaridade como necessidade e como problema nas ciências sociais. Revista Ideação, v.10, n.01, p. 41-62, 2008. Disponível: <http://e-revista.unioeste.br/index.php/ideacao/article/view/4143> Acesso: 25.07.2018.

FUNDAÇÃO NACIONAL DO ÍNDIO - FUNAI. Estatuto dos povos indígenas [proposta].Disponível: <http://www.funai.gov.br/arquivos/conteudo/presidencia/pdf/Estatuto-do-Indio_CNPI/Estatuto_Povos_Indigenas-Proposta_CNPI-2009.pdf> Acesso: 18.02.2017.

GUERRA, J. G. A. Mendonça do Amarelão: os caminhos e descaminhos da identidade indígena no Rio Grande do Norte. Recife/PE: UFPE, 2007 (Dissertação de Mestrado). Disponível: <ftp://ftp.ufrn.br/pub/biblioteca/ext/bdtd/JussaraGAG.pdf> Acesso: 16.10.2016.

. J. G. A. Mendonça do Amarelão: Origem, migrações, aspectos de sua cultura e identidade étnica. João Pessoa: Ideia, 2017.

GOMES, M.P. O caminho brasileiro para a cidadania indígena. In: PINSKY, Jaime; PINSKY, Carla Bassanezi. História da cidadania. 5.ed. São Paulo: Contexto, 2010.

GORAYEBE, A; MEIRELES, A.J.A.; SILVA, E.V. Princípios básicos de cartografia e construção de mapas sociais: metodologias aplicadas ao mapeamento participativo. In: GORAYEB, A.; MEIRELES, A.J.A.; SILVA, E.V. da. (Org) Cartografia Social e Cidadania: experiências de mapeamento participativo dos territórios de comunidades urbanas e tradicionais. Fortaleza: Expressão Gráfica Editora, 2015. p. 09-24.

IBGE - INSTITUTO BRASILEIRO DE GEOGRAFIA E ESTATÍSTICA. Os indígenas no Censo Demográfico 2010: primeiras considerações com base no quesito cor ou raça. Trabalho elaborado em comemoração ao Dia do Índio. Disponível: <http://www.ibge.gov.br/indigenas/indigena_censo2010.pdf.> Acesso em 18.11.2016.

IBGE Cidades. 2017. Disponível em <https://cidades.ibge.gov.br/brasil/rn/joao-camara/panorama>. Acesso: 27.07.2018.

MACEDO, H.A.M. Populações indígenas no sertão do Rio Grande do Norte: história e mestiçagens. Natal-RN: EDUFRN, 2011.

MEIRELES, A.J.A. Unidades de paisagem na Terra indígena Tremembé de São José e Buriti, Município de Itapipoca-CE. In: SILVA, E.V.; MEIRELES, A.J.A.; GORAYEB, A. (org.) Educação ambiental e indígena: caminhos da extensão universitária na gestão de comunidades tradicionais. Fortaleza: Edições UFC, 2011.

MONTEIRO, D.M. Introdução à história do Rio Grande do Norte. 4.ed. Natal-RN: Flor de Sal, 2015. NOVA CARTOGRAFIA SOCIAL DA AMAZÔNIA. 2014. Disponível: <http://novacartografiasocial.com/> Acesso: 06.08.2017.

ONU - ORGANIZAÇÃO DAS NAÇÕES UNIDAS. Declaração sobre os direitos dos povos indígenas. 2007. Disponível: <http://www.direitoshumanos.usp.br/index.php/ Direito-dos-PovosInd\%C3\%ADgenas/declaracao-das-nacoes-unidas-sobre-os-direitos-dos-povos-indigenas.html> 
Acesso: 21.07.2017.

OIT - ORGANIZAÇÃO INTERNACIONAL DO TRABALHO Escritório do Brasil. Convenção n 169 sobre povos indígenas e tribais e Resolução referente à ação da OIT. Brasília, 2011. Disponível: < http://portal.iphan.gov.br/uploads/ckfinder/arquivos/ Convencao_169_OIT.pdf> Acesso: 21.07.2017.

OLIVEIRA, J. N. V. Revista de Humanidades: "ser índio" e "ser caboclo" potiguar: história indígena e o processo identitário nas comunidades dos caboclos do Assú. v.15, n.35, p.191-197, 2014. Disponível: < https://periodicos.ufrn.br/mneme/article/view/7819> Acesso: 16.10.2016.

PEREIRA, M. G. N. Potiguaras de Sagi: da invisibilidade ao reconhecimento étnico. Natal/RN: UFRN, 2015 (Dissertação de Mestrado). Disponível: <https://repositorio.ufrn.br/jspui/handle/123456789/20325> Acesso: 16.10.2016.

POSEY, D.A.; FRECHIONE, J.; EDDINS, J.; SILVA, L.F.; MYERS, D.; CASE, D.; MACBEATH, P. Ethnoecology as applied anthropology in Amazonian development. Human Organization, v.43, n. 2, p. 95107, 1984. Disponível: <https://www.academia.edu/13703139/Ethnoecology_as_Applied_Anthropology_in_Amaz onian_Development> Acesso: 28.07.2017.

PRADO, H.M.; MURRIETA, R.S.S. A etnoecologia em perspectiva: origens, interfaces e correntes atuais de um campo em ascensão. Ambiente e sociedade [online]. 2015, vol.18, n.4, p.139-160. Disponivel: $\quad<$ http://www.scielo.br/scielo.php?script=sci_arttext \&pid=S1414 753X2015000400009> Acesso: 30.07.2017.

QGIS - Quantum Geographic Information System. Open Source Geospatial Foundation Project (OSGeo). Versão 2.14. Disponível: <https://www.qgis.org/pt_BR/site/forusers/ download.html> Acesso: 08.11.2017.

RICHARDSON, R.J. et al. Pesquisa Social: métodos e técnicas. 3.ed. São Paulo: Atlas, 2014.

RIU-BOSOMS, C.; AMAT, T.V.; DUANE, A.; LLAMAZARES, A.F.; GUĖSE, M.; LUZ, A.C.; MACIA, M.J.; GÁLVEZ, J.P.; GARCIA, V.R. Exploring indigenous landscape classification across different dimensions: a case study from the Bolivian Amazon. Landsc Research. n. 40, v. 3, 2015. p. 318-337. Disponível: <https://www.ncbi.nlm.nih.gov/pmc/articles /PMC4374147/> Acesso: 06.08.2017.

RODRIGUEZ, J.M.M.; SILVA, E.V. Planejamento e Gestão Ambiental: subsídios da Geoecologia das paisagens e da teoria geossistêmica. 2.ed. Fortaleza: Edições UFC, 2016.

SACHS, I. De volta à mão visível: os desafios da Segunda Cúpula da Terra no Rio de Janeiro. Estudos avançados. São Paulo, v. 26, n.74, p. 5-20, 2012. Disponível em <http://www.scielo. br/scielo.php?script=sci_arttext\&pid=S0103-40142012000100002 \&lng =pt\&nrm=iso>. Acesso: 04.11.2017.

SANTOS, B.S. A territorialização/desterritorialização da exclusão social no processo de construção de uma cultura emancipatória. In: Seminário "Estudos territoriais de desigualdades sociais". PUC/SP, 2001. Disponível em <http://www.dpi.inpe.br/ geopro/exclusao/Boaventura.pdf> Acesso: 04.07.2018.

. Para além do pensamento abissal: das linhas globais a uma ecologia de saberes. In: SANTOS, Boaventura de Sousa; MENESES, Maria Paula (Org.) Epistemologias do Sul. São Paulo: Cortez, 2010.

SILVA, M. Ivoneide S. Entrevista concedida a MARTINS, J.C.V. João Câmara-RN, 02 out. 2017.

SILVA, C. M. M. Em busca da realidade: a experiência da etnicidade dos eleotérios, Catu-RN. 
Natal/RN: UFRN, 2007 (Dissertação de Mestrado). Disponível: <http://portal.ifrn.edu.br/campus/canguaretama/observatorio-da-diversidade/banco-de-<monografias-sobre-a-diversidade/embusca-da-realidade201d-a-experiencia-da-etnicidade-dos-eleoterios-catu-rn-1/at_download/file> Acesso: 17.10.2016.

SILVA, M.E.C; LOPES, J.B.; BARROS, R.F.M.; ALENCAR, N.L.; MENDES, L.M.S. A etnoconservação no contexto da agrobiodiversidade: diálogos entre os saberes científicos e locais em tempos de crise ambiental. Espacios. v. 37, n. 37, 2016. Disponível em <http://www.revistaespacios.com/a16v37n37/16373703.html> Acesso: 30.07.2017.

SOUZA, G.C.; BASSI, J.B. e KUBO, R.R. Etnoecologia: dimensões teórica e aplicada. In: SOUZA, G.C. (org.) Transformações no espaço rural. Porto Alegre: Editora da UFRGS, 2011. Disponível: <http://www.ufrgs.br/cursopgdr/downloadsSerie/derad025.pdf\#page=25> Acesso: 29.07.2017.

STALLAERT, C. Boruca behind the Mask. Empoderamiento, etnodesarrollo y etnorresistencia en una comunidad indígena costarricense. Journal of Iberian and Latin American Research. Volume 22, 2016. Disponível: <http://journal-dl.com/item/591088 603fbb6e137440a82f> Acesso: 05.08.2017.

VIEIRA, J.G. Entrevista concedida a COSTA, A.M.M. e SANTOS, S.C.M. Revista Inter-legere. n.10, p.619, 2012. Disponível: <http://www.cchla.ufrn.br/interlegere/10/pdf/10db 01.pdf> Acesso: 15.10.2016.

VIEIRA, J. G.; KÓS, C. Invisibilidade, resistência e reconhecimento. In: RICARDO B.; RICARDO F. Povos Indígenas do Brasil 2011/2016. São Paulo: Instituto Socioambiental 2017 (p.519-522). 